\title{
Adaptations to general surgery resident education in response to COVID-19
}

\author{
Vivian Ma, MD \\ Tracy Scott, MD, MHPE \\ Michael Ott, MD, MSc \\ Ahmer Karimuddin, MD, MAEd
}

Accepted April 27, 2021

\section{Correspondence to: \\ V. Ma \\ Department of Surgery \\ Faculty of Medicine \\ 2775 Laurel St, 11th floor \\ Vancouver BC V5Z $1 \mathrm{M} 9$ \\ vivianma@alumni.ubc.ca}

Cite as: Can J Surg 2021 October 26; 64(5). doi $10.1503 /$ cjs. 023320
Background: The COVID-19 pandemic led to many new provincial public health measures to reallocate resources in response to an impending surge of cases. These necessary decisions had several downstream effects on general surgery training. We surveyed the actions taken by Canadian general surgery training programs in response to the COVID19 pandemic.

Method: A mixed-methods survey was sent to all general surgery program directors to assess various domains in surgical education and modifications made because of the pandemic. Responses were quantified as proportions or qualitative narratives describing those changes.

Results: Most programs (13/15) recalled residents from planned rotations and redistributed them to rotations considered as core required services, including acute care surgery, trauma surgery and intensive care. Many programs also restructured their acute care surgery models to allow for a group of "reserve" residents to replace trainees who became infected with SARS-CoV-2. In terms of clinical experience, there was a reduction in both clinical and operative exposure among trainees. The reduction in clinical exposure disproportionately affected junior residents, whose involvement in COVID-19 cases was restricted. Formal educational sessions were maintained, but delivered virtually. Many programs instituted a program of increased frequency of communication with trainees.

Conclusion: Many programs embraced using virtual platforms for teaching. The demonstrated utility of virtual teaching may lead to rethinking how training programs deliver didactic teaching and expand teaching opportunities. However, many programs also perceived a decrease in clinical and procedural exposure, primarily affecting junior residents. More information is needed to quantify the deficit in learning incurred as a result of the pandemic as well as its long-term effects on resident competency.

Contexte : La pandémie de COVID-19 est à l'origine de plusieurs nouvelles mesures de santé publique à l'échelle des provinces qui ont permis de réassigner les ressources et de prendre en charge la hausse des cas anticipée. Ces décisions inévitables ont eu différentes répercussions en aval, sur la formation en chirurgie générale. Nous avons pris connaissance des initiatives prises par les programmes canadiens de formation en chirurgie générale en réponse à la pandémie de COVID-19.

Méthodes : Une enquête multiméthode a été menée auprès de tous les directeurs de programmes de chirurgie générale pour évaluer différents secteurs de la formation en chirurgie et les modifications qui y ont apportées en raison de la pandémie. Les réponses ont été enregistrées sous forme de proportions ou de descriptions qualitatives de ces modifications.

Résultats : La plupart des programmes (13/15) ont remplacé les stages prévus de leurs résidents par une réassignation vers les services dits essentiels, soit chirurgies d'urgence, traumatologie et soins intensifs. Plusieurs programmes ont aussi restructuré leurs modèles de chirurgie d'urgence pour constituer un groupe de résidents «réservistes» capables de remplacer ceux qui contractaient le SRAS-CoV-2. Pour ce qui est de l'expérience clinique, on a noté une baisse de l'exposition des résidents aux situations cliniques et chirurgicales. La réduction de l'exposition aux situations cliniques a pénalisé les résidents juniors de façon disproportionnée car leur rôle auprès des cas de COVID19 était restreint. Les formation magistrales ont été maintenues, mais offertes sous forme virtuelle. Plusieurs programmes ont instauré un système de communications plus fréquentes avec leurs résidents.

Conclusion : De nombreux programmes ont adopté des plateformes d'enseignement virtuelles. L'utilité avérée de l'enseignement à distance pourrait forcer la réflexion sur la façon d'offrir l'enseignement magistral et diversifier les façons de livrer la matière. Par contre plusieurs programmes ont aussi perçu une diminution de l'exposition aux situations cliniques et aux interventions affectant surtout les résidents juniors. Il faudra recueillir plus de données pour quantifier le déficit d'apprentissage encouru en raison de la pandémie et ses effets à long terme sur la compétence des résidents. 
$\mathbf{S}$ ARS-CoV-2 is the novel respiratory virus responsible for the global COVID-19 pandemic. ${ }^{1,2}$ While symptoms, such as a cough and fever, may be mild, some individuals develop acute respiratory distress syndrome, pneumonia, septic shock and multi-system organ failure requiring intensive care. ${ }^{1}$ SARS-CoV-2 is spread between humans by respiratory droplets and is more infectious than seasonal influenza, with the basic reproductive number varying between 1.4 and $6.57 . .^{1-4}$ This has led to more than 240 million confirmed cases to date, worldwide. ${ }^{5}$

The first cluster of 27 cases was identified in Wuhan, China, on Dec. 31, 2019, and the first Canadian case was identified in Toronto on Jan. 23, 2020. ${ }^{1,2,6}$ COVID-19 was declared a global pandemic on Mar. 11, 2020, and in response, the Canadian government implemented border restrictions and many provinces declared a state of emergency. ${ }^{7-14}$ While all provinces had documented cases of COVID-19, the degree to which COVID-19 affected their health care systems varied, resulting in many provincial lockdowns with differing degrees of restrictions. ${ }^{10-14}$ Nonessential services, including elective surgeries, were paused in an effort to conserve personal protective equipment in the event of an exponential surge in cases. ${ }^{15-17}$ Similarly, attempts were made to increase available health care workers, including residents, should hospitals become overwhelmed with patients with COVID-19.

The necessary redistribution of resources to meet a predicted surge affected residency training in many different ways. Residents were recalled to central health care institutions to increase the number of workers in the event of a surge. For surgical residency training programs, this often translated to residents being recalled from an elective operative rotation to service intensive care units (ICUs) or emergency departments (EDs). Furthermore, many institutions cancelled elective surgeries to conserve resources and hospital beds, leading to an unprecedented decrease in the volume of available procedures for trainees to participate in. ${ }^{15-17}$ The increased predicted service needs also had to be balanced with maintaining trainee wellness, so many clinical services and rotations had to be remodelled to limit the spread of SARS-CoV-2 among trainees.

The province-to-province variability of public health measures and regulations made the adaptations of general surgery training programs highly contextual to the local situation. As a result, the adaptations made to training were not uniform. The purpose of this study was to assess and catalogue the changes made to general surgery training programs across Canada, allowing for an understanding of both positive and negative effects of the COVID-19 pandemic on education.

\section{Methods}

A 27-question qualitative survey (Appendix 1, available at canjsurg.ca/) was created to evaluate the following domains: baseline residency program demographics, structural changes to the learning environment, clinical exposure for general surgery residents, changes to organized educational sessions, and wellness of general surgery residents.

The survey was sent to all 17 general surgery residency program directors in Canada 3 weeks from the initial general declaration of provincial states of emergency in response to the COVID-19 pandemic in Canada. Responses were collected from April 12 to May 13, 2020. Results were then compiled and analyzed according to the previously mentioned domains. Categorical data are represented as proportions where appropriate, supplemented by narrative responses.

\section{REsults}

Most (15/17 [88.2\%]) Canadian general surgery residency program directors responded to the survey (Table 1 ). Thirteen $(86.7 \%)$ of those programs recalled residents from their scheduled rotations.

Several (11/14 [78.6\%]) programs perceived a decrease in the volume of general surgery emergencies since the beginning of the COVID-19 pandemic; 3 (21.4\%) programs perceived no change.

\section{Educational environment}

Recalled residents from 7 of 12 (58.3\%) programs were redistributed, primarily to cover 1 or more core rotations, including acute care surgery (ACS), trauma and intensive care. Four programs ensured that residents were redistributed for those core services, but also had residents on surgical subspecialty rotations, including hepatopancreaticobiliary, colorectal and pediatric surgery.

Table 1. Canadian general surgery programs that responded or did not respond to the survey assessing changes to

surgical education for general surgery residents in response to the COVID-19 pandemic

\begin{tabular}{ll} 
Programs that responded & Programs without a response \\
\hline University of British Columbia & Northern Ontario School of \\
University of Calgary & Medicine \\
University of Alberta & Université de Montréal \\
University of Saskatchewan & \\
University of Manitoba & \\
Western University & \\
McMaster University & \\
University of Toronto & \\
Queen's University & \\
University of Ottawa & \\
McGill University & \\
Université de Sherbrooke & \\
Université Laval & \\
Dalhousie University & \\
Memorial University of Newfoundland &
\end{tabular}


Most programs restructured their ACS models in some way, with 11 of $12(91.7 \%)$ programs increasing the overall number of residents on ACS. In terms of changes made to their ACS models, the approach varied, with some programs changing the number of ACS teams or changing the number of junior or senior residents per team. One program disbanded the ACS system, and the resident serving as head of the general surgery service collaborated on a daily basis with staff and the internal medicine service to allocate residents based on need.

Furthermore, most programs created a dedicated "reserve" pool of residents to replace trainees who became infected with SARS-CoV-2. Among programs without a dedicated reserve pool of residents, 2 programs had research residents or residents on leave who were designated as back-up should the need arise.

\section{Clinical environment}

In 12 of $14(85.7 \%)$ programs, all general surgery residents assigned to a clinical service were not necessarily working every day. Based on the survey responses, most programs attempted to limit resident presence in the hospital wherever necessary. This included a rotating system for residents on service where they would work for 1-2 weeks, followed by a week off. Attempts were also made to maintain specific junior-senior pairs for call to limit contact. Some programs had residents round only on their team's patients, but only the on-call team was expected to stay in-house after rounding, whereas other programs only had the on-call team working on any given day. Elective cases that involved residents were often oncology cases (e.g., breast, colorectal cancers), where senior residents may be assigned to assist, or residents could sign up if their schedule permitted.

\section{Clinical exposure}

New consults who tested positive for SARS-CoV-2 were triaged by either the senior resident or staff physician at 12 of $13(92.3 \%)$ programs for emergency consults and 13 of $14(92.8 \%)$ programs for new inpatient consults (Figure 1). They were similarly first seen by the senior resident or staff physician in most programs. This was in contrast to new consults who tested negative for SARS-CoV-2 or those who had no symptoms and had not been tested (COVID status unknown), where the junior resident was exclusively first call in most programs (9/13 [69.2\%] emergency consults and inpatient consults) and was first to see these patients $(7 / 14$ [50\%] emergency consults, 10/14 [71.4\%] inpatient consults) (Figure 2).

This was consistent with rounds on postoperative patients who were SARS-CoV-2-positive, who were seen by either staff or the senior resident in 10 of 13 (76.9\%) programs, and those who tested negative or whose COVID status was unknown, who were seen by either a junior or senior resident at 8 of $14(57.1 \%)$ programs or either the junior or senior resident or staff physician at 5 of 14 (35.7\%) programs (Figure 3).

Residents were not scheduled for Telehealth or virtual clinics at 12 of 15 (80\%) programs. However, 1 of those programs continues to hold in-person clinics, though it is unclear if residents were involved.

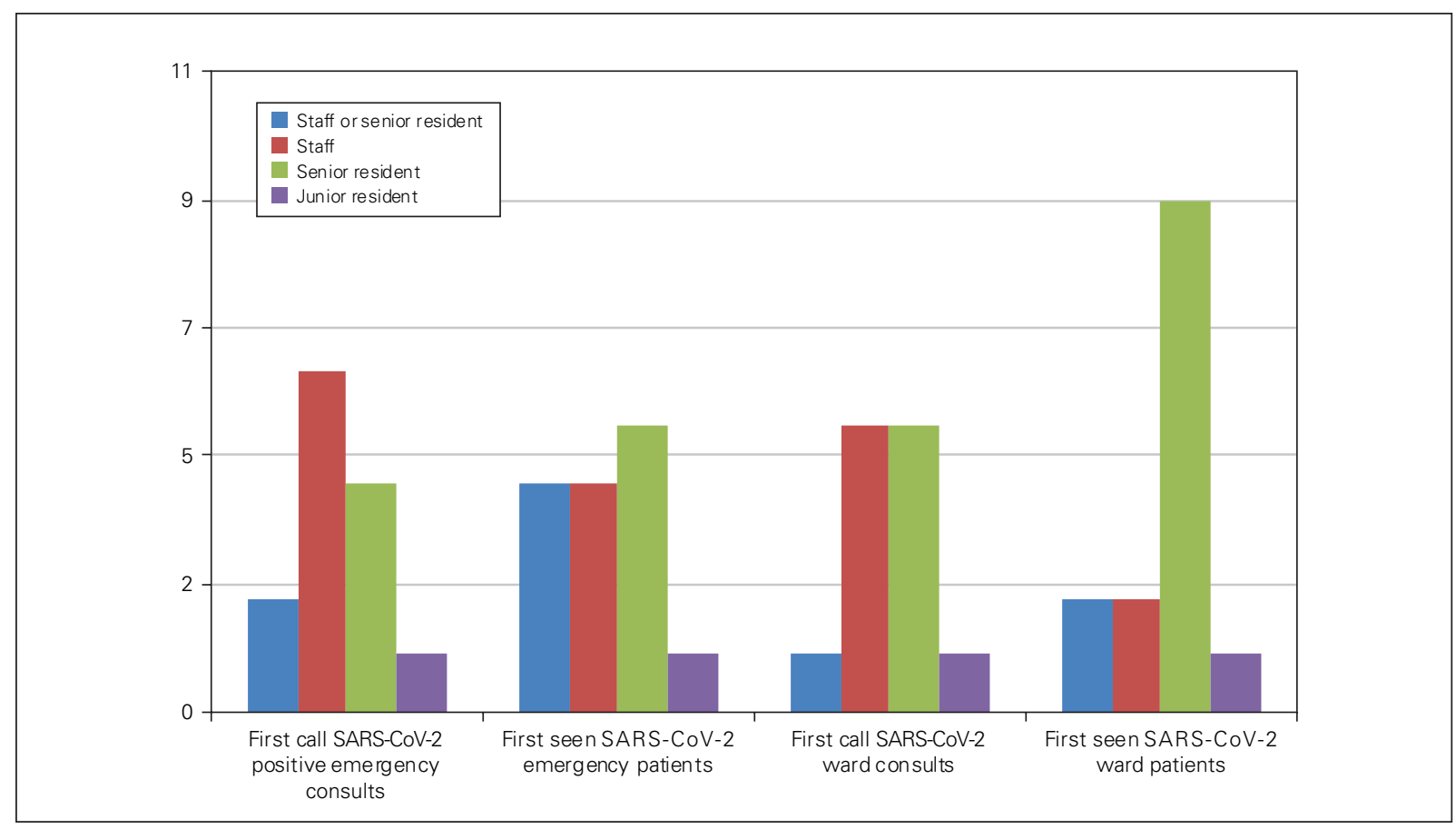

Fig. 1. Roles for first call or seeing new consults who tested positive for SARS-CoV-2. 


\section{Procedural exposure}

In terms of operating, there was a national focus on maintaining only 1 learner per case. Eleven of 14 (78.6\%) programs had 1 learner scrubbed, and the remaining $3(21.4 \%)$ programs had a maximum of 2 learners scrubbed. This included junior- (e.g., laparoscopic appendectomy) and senior-level operations (e.g., colectomy). Given the shift in clinical exposure, which saw junior residents less involved in cases or suspected cases of COVID-19, and given that operations were mostly limited to a single learner, procedural exposure was perceived to have decreased for junior trainees.

Fourteen of $15(93.3 \%)$ programs continued to formally evaluate residents for their clinical rotations during the COVID-19 pandemic.

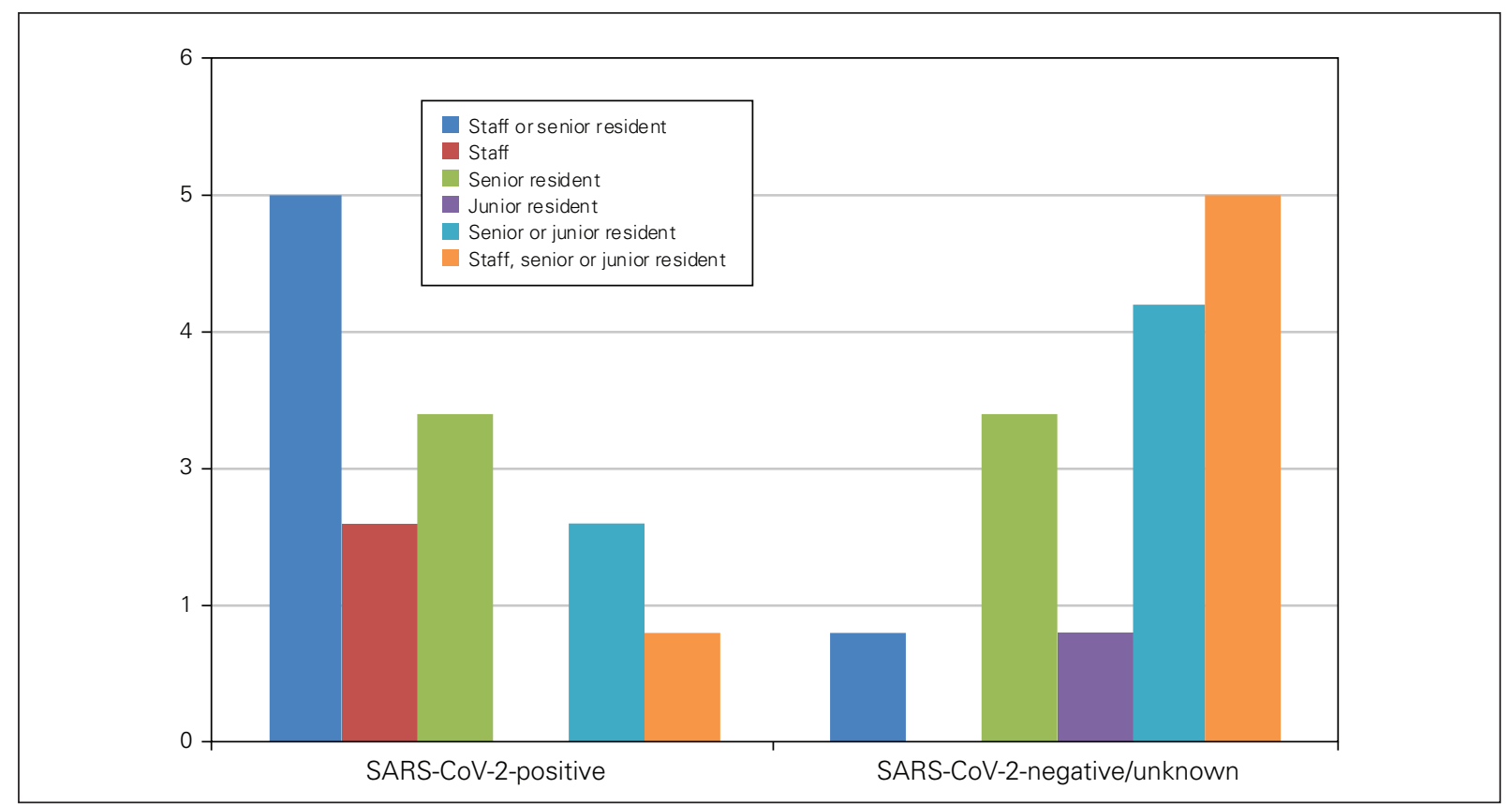

Fig. 2. Roles for first call or seeing new consults who tested negative for SARS-CoV-2 or those who had no symptoms and had not been tested (COVID status unknown).

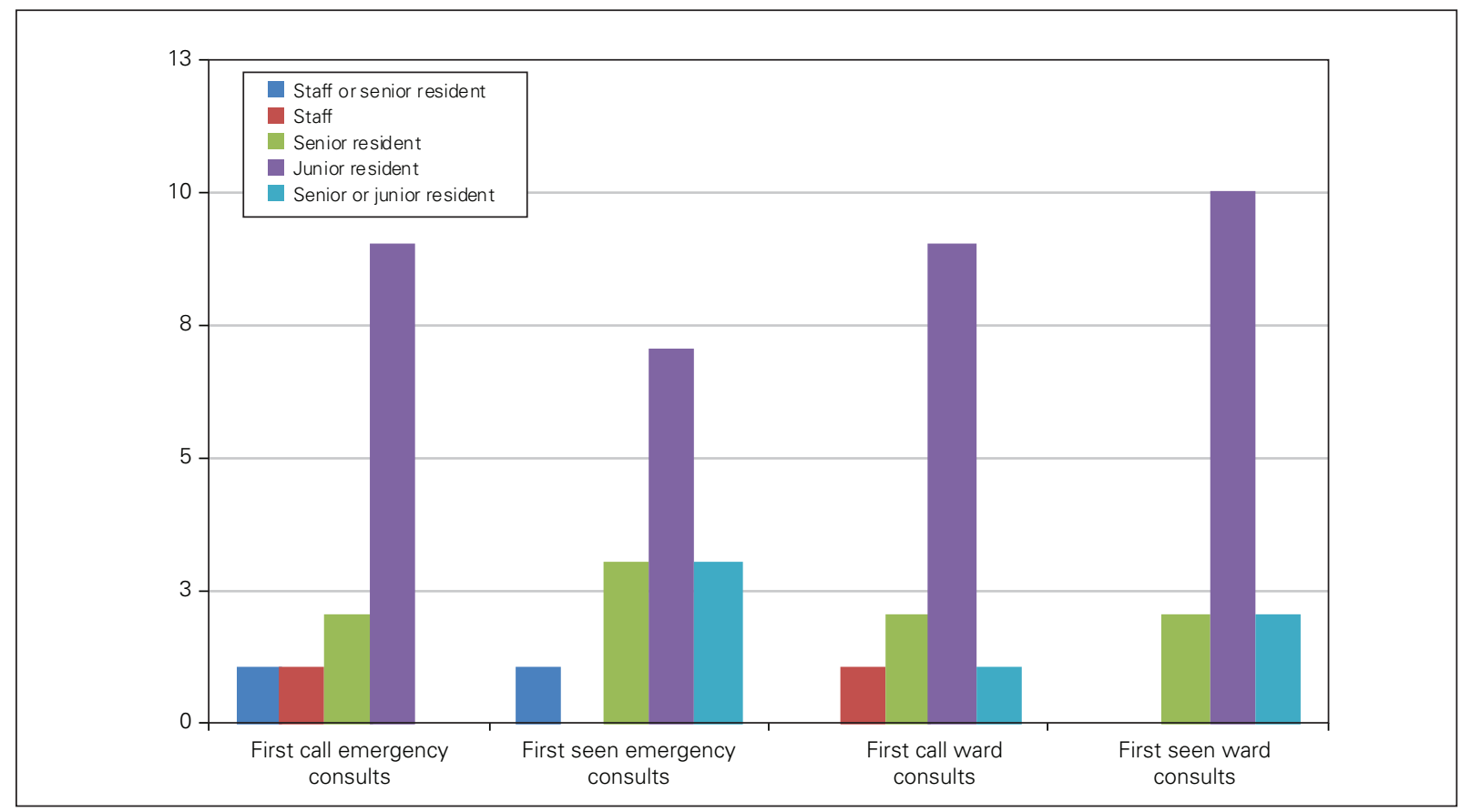

Fig. 3. Roles for rounding on surgical inpatients. 


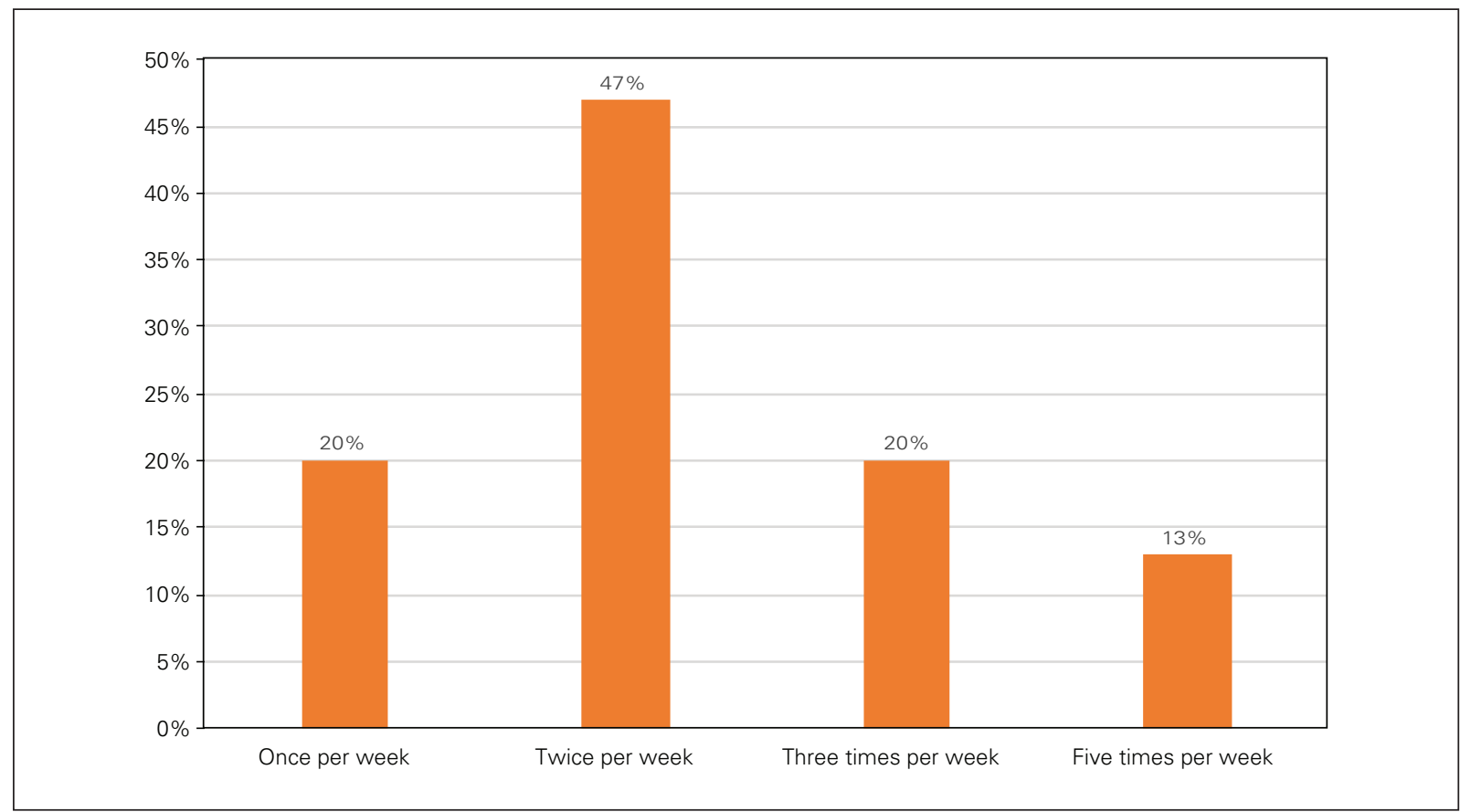

Fig. 4. Frequency of virtual teaching sessions in a given week.

\section{Education}

Fourteen of 15 (93.3\%) programs continued to hold academic teaching sessions, with all programs delivering them virtually. All programs also had some form of additional virtual teaching rounds held at varying frequencies (Figure 4).

\section{Wellness}

During the COVID-19 pandemic, 8 of 15 (53.3\%) programs were meeting with residents on an as-needed basis. Seven of 15 (46.7\%) programs regularly met with residents as a group, which occurred weekly for 4 (57.1\%) programs and biweekly for $2(28.6 \%)$ programs.

Vacations were temporarily suspended for 5 of 15 (33.3\%) programs.

\section{Discussion}

The COVID-19 pandemic created an unprecedented crisis for health care in Canada. This extended to the clinical and academic milieu of general surgery residency programs across the country. Our survey identified that during this pandemic, all general surgery residency programs across the country prioritized resident wellness. While provision of clinical services was necessary, many programs made structural changes to limit potential resident exposure to SARSCoV-2, primarily having senior residents or staff triage and see new general surgery consults who were confirmed or suspected to have SARS-CoV-2 infection and limiting involvement in all surgical procedures to only 1 resident. Further, some programs restructured their acute care surgery service in response to the pandemic, presumably to minimize resident exposure to SARS-CoV-2. While limiting resident exposure may have been in part be due to conservation of resources such as personal protective equipment or to an overall decrease in clinical volume, as perceived by program directors in the survey, it may also have reflected a concern about residents contracting SARS-CoV-2 and potentially spreading the virus among trainees. This concern is reflected by the creation of "reserve" pools, which was a nearuniversal response in programs across the country. These reserve pools were residents who were isolated from clinical activities for days to weeks, to ensure that if other residents contracted SARS-CoV-2 or needed to self-isolate, clinical services in areas of critical need could continue. Furthermore, by creating teams of residents who rotated on and off clinical activities, exposure to SARS-CoV-2 was mitigated.

However, prioritizing resident wellness by limiting clinical exposure has led to decreased clinical and procedural exposure, which is a crucial aspect in training for a technical specialty. Though the exact deficit has not been quantified, the perceived decrease in general surgery emergencies, public health cessation of elective cases, limiting the number of residents involved in each operation, and recalling residents from nonessential rotations to serve core services, such as ICU or internal 
medicine, residents' procedural exposure and patient encounters are inferred to have decreased overall. While clinical education can be partially delivered in a virtual classroom setting, procedural exposure in the operating room or endoscopy suite is essential to learning the technical aspects of general surgery. Furthermore, reductions in outpatient clinical encounters may affect the resident learning experience and learning. This may be mitigated through virtual clinics, but the effect of virtual clinics on competency development will have to be determined in the longer term. A limited amount of tactical training can be supplemented by simulations.

The downstream effects of decreased clinical exposure on residency training are unknown, especially given that the pandemic has not yet concluded. As such, further investigation into the losses incurred during the pandemic are required by quantifying case tallies during the initial months of the pandemic compared with numbers before the pandemic. However, a decrease in cases may not necessarily translate into quantifiable deficits in competency. Future studies comparing the competence and confidence to perform specific operations between surgeons who completed their training before the COVID-19 pandemic and those who completed it afterwards may elucidate the ultimate effects on technical competency. Furthermore, perhaps rotating residents through the core rotations in cohorts, rather than having a dedicated reserve pool, may ensure equal distribution of procedural opportunities. This may require significant attention, as Canadian general surgery residency programs recently adopted the Competence by Design educational model in the 2020-21 academic year.

In terms of organized education sessions, most programs were able to maintain both weekly resident teaching sessions and additional teaching rounds of some form at varying frequencies. Because of COVID19 restrictions, these sessions were uniformly delivered virtually, demonstrating a potential new modality for didactic surgical teaching. While further information is needed to evaluate the effectiveness of virtual education for general surgery residency programs, our survey shows that it is a viable alternative to traditional inperson lectures. The benefits of virtual education include an increase in attendance, given the easy access regardless of location. Cho and colleagues corroborated such findings, finding that $92.5 \%$ of attendees reported an excellent or good experience with virtual lectures. ${ }^{18}$ Furthermore, virtual teaching was not limited to local lecturers, but allowed for more opportunities to learn from national leaders in a field. ${ }^{18}$ This exposure leads to potential for a national curriculum and nationally organized teaching events. However, the effectiveness of a unified curriculum will need to be evaluated, and challenges in terms of timing and maximizing attendance will need to be considered. Drawbacks to virtual lectures include the lack of interaction between attendees and lecturers as well as issues regarding patient privacy and scheduling. ${ }^{18}$ This format, in turn may promote didactic lectures as opposed to an interactive teaching session. Although the delivery of virtual education appears to be a promising new modality with many opportunities beyond those of traditional didactic lectures, further evaluation surveying both general surgery residents and lecturers about their experience with virtual lectures is required to assess whether similar results can be obtained given the differences among programs. Finally, perhaps virtual learning may be extended to include clinic attendance by residents through telehealth - an area underutilized during the first wave of the pandemic - to help supplement and increase clinical exposure. Although virtual clinic attendance may be limited given that certain general surgery pathologies are dependent on the clinical exams (e.g., breast mass, inguinal hernia), it can continue provide some clinic exposure within the boundaries presented by the COVID-19 pandemic.

\section{Conclusion}

Our survey results showed that adaptations to surgical learning were based on local context and varied provincial regulations during the COVID-19 pandemic. Universally, surgical education has been affected primarily through a decrease in clinical and procedural exposure, with unknown long-term effects on resident competency. However, most programs have prioritized resident wellness, an aspect that surgical training programs are often accused of giving less priority. Best practices and novel methods of delivering education virtually are being implemented and refined in many training programs.

Acknowledgements: The authors thank the general surgery program directors for their participation and contribution in the survey.

Affiliations: From the Department of General Surgery, University of British Columbia, Vancouver, BC (Ma, Karimuddin); and the Department of General Surgery, Western University, London, Ont. (Ott).

\section{Competing interests: None declared.}

Contributors: All authors designed the study. V. Ma and A. Karimuddin acquired the data, which all authors analyzed. All authors wrote and reviewed the article and gave final approval of the version to be published.

Content licence: This is an Open Access article distributed in accordance with the terms of the Creative Commons Attribution (CC BY-NC-ND 4.0) licence, which permits use, distribution and reproduction in any medium, provided that the original publication is properly cited, the use is noncommercial (i.e., research or educational use), and no modifications or adaptations are made. See: https://creativecommons.org/licenses/by-nc-nd/4.0/ 


\section{References}

1. Yuki K, Fugiogi M, Koutsogiannaki S. COVID-19 pathophysiology: a review. Clin Immunol 2020;215:108427.

2. Heng L, Liu S, Yu X, et al. Coronavirus disease 2019 (COVID-19): current status and future perspectives. Int 7 Antimicrob Agents 2020;55:105951.

3. Liu Y, Gayle A, Wilder-Smith A, et al. The reproductive number of COVID-19 is higher compared to SARS coronavirus. 7 Travel Med 2020;27: taaa021.

4. Sanche S, Lin YT, Xu C, et al. High contagiousness and rapid spread of severe acute respiratory syndrome coronavirus 2. Emerg Infect Dis 2020;26:1470-7.

5. WHO COVID-19 Dashboard. Geneva: World Health Organization, 2020. Available: https://covid19.who.int/ (accessed 2021 Oct 14).

6. Marchang-Senecal X, Kozak R, Mubareka S, et al. Diagnosis and management of first case of COVID-19 in Canada: lessons applied from SARS-CoV-1. Clin Infect Dis 2020;71:ciaa227.

7. World Health Organization. Statement on the second meeting of the International Health Regulations (2005) Emergency Committee regarding the outbreak of novel coronavirus $(2019-\mathrm{nCoV})$. WHO; Jan. 30, 2020. Available: https://www.who.int/news -room/detail/30-01-2020-statement-on-the-second-meeting-of -the-international-health-regulations-(2005)-emergency-committee -regarding-the-outbreak-of-novel-coronavirus-(2019-ncov) (accessed 2020 Sept. 6).
8. WHO Director-General's opening remarks at the media briefing on COVID-19. WHO; Mar. 11, 2020.

9. Meyer C. Canada closing border to most non-citizens to slow COVID-19. National Observer 2020 Mar. 16.

10. Zussman R. BC declares state of emergency in response to coronavirus pandemic. Global News 2020 Mar. 18.

11. Block E, Goldenberg A, Waschuk G. COVID-19: Can they do that? Part IV: Alberta's Public Health Act and Emergency Management Act." McCarthy Tetrault; 2020 Mar. 19.

12. Rodrigues G. Ontario government declares state of emergency amid coronavirus pandemic. Global News 2020 Mar. 17.

13. ICI Grand Montréal. Montreal declare l'etat d'urgence. Radio Canada 2020 Apr. 5

14. State of emergency delared in response to COVID-19, seven new cases. Government of Nova Scotia, Canada; 2020 Mar. 23.

15. Zussman R. Coronavirus: B.C. to cancel all non-urgent surgeries to free up beds for possible patients. Global News 2020 Mar. 16.

16. Shah $M$. Ontario asking hospitals to ramp down elective surgeries in preparation for COVID-19. Global News 2020 Mar. 15.

17. Barua B, Moir M. COVID creating a backlog of cancelled elective surgeries in Canada. Fraser Institute; 2020 Apr. 14. Available: https://www.fraserinstitute.org/blogs/covid-creating-a-backlog-of -cancelled-elective-surgeries-in-canada (accessed 2020 Sept. 10).

18. Cho MJ, Hong JP. The emergence of virtual education during the COVID-19 pandemic: The past, present, and future of the plastic surgery education. 7 Plast Reconstr Aesthet Surg 2021;S17486815:00033-4. 